\title{
La formación de profesionales universitarios en información y documentación desde una nueva perspectiva: la tercera edad
}

\author{
Cristina Faba-Pérez* \\ Rocío Patiño-Agudo*
}

Artículo recibido: 23 de diciembre de 2014.

Los descubrimientos médicos y las mejoras en la calidad de vida han hecho que la esperanza de vida, en la mayoría de los países, aumente considerablemente. La tercera edad es uno de los grupos donde más se ha notado este progreso. La universidad no puede ni debe ser ajena a este profundo cambio social, por lo que los nuevos títulos de las universidades españolas, independientemente de su disciplina, deberían incluir contenidos referentes a este colectivo, con el fin de abrir nuevas vías para las salidas profesionales de sus

* Ambas autoras forman parte del Departamento de Información y Comunicación, Facultad de Ciencias de la Documentación y la Comunicación, Universidad de Extremadura, Badajoz, España. cfabper@unex.es y rpatinoagudo@gmail.com 
egresados y, más aún, los relacionados directamente con la sociedad y las tecnologías de la información y la comunicación. Por ello, el objetivo fundamental de este trabajo es adaptar el actual título de grado en Información y Documentación de la Universidad de Extremadura a nuevas oportunidades profesionales, que parecen pasar desapercibidas a pesar de su importancia y constante crecimiento. Con este fin, se diseñan contenidos especializados en la tercera edad para un total de 40 asignaturas. Estos contenidos no suplen a los ya existentes, sino que se añaden a ellos y son extrapolables a otros estudios universitarios en Información y Documentación impartidos más allá de nuestras fronteras geográficas.

Palabras clave: Grado en información y documentación; Tercera edad; Diseño de contenidos; Salidas profesionales; Universidad de Extremadura.

\section{Abstract}

The Training of Professionals in the Information Sciences from A New Perspective: Seniors

Cristina Faba-Pérez and Rocío Patiño-Agudo

The medical advances have increased life expectancy in most countries. Seniors are the group that has greatly noticed this progress. The university cannot ignore this profound social change. New degrees of Spanish universities should include content related to this group to open new professional opportunities for graduates, mainly degrees directly related to the information society and information technologies and communication such as the degree of information sciences. Therefore, the main objective of this study is to adapt the current degree of Information Sciences from the University of Extremadura to new professional opportunities. To this end, specialized contents in seniors are designed for a total of 40 subjects. These contents do not replace the existing, but added to them, being extrapolated to other university studies in information and documentation beyond our geographical boundaries.

Keywords: Degree of Information Sciences; Seniors; Content Design; Professional Opportunities; University of Extremadura. 

(6.72\% en 1991 a un $10.27 \%$ en 2012 en personas mayores de 67 anos. Desde $16.72 \%$ en 1991 a un $10.27 \%$ en 2012 en personas mayores de 67 años. Desde el punto de vista internacional, la Organización Mundial de la Salud (OMS), ${ }^{3}$ señala que hacia 2050 el 20\% de la población mundial estará compuesta por adultos de la tercera edad, por lo que es necesario prestar mayor atención a sus necesidades.

Hay diversas perspectivas a la hora de referirse a la tercera edad, ya sea para establecer una definición de la misma, para utilizar una única denominación para acotar su franja de edad. Con respecto a su delimitación, en 1980, Fustinoni y Pasanante ${ }^{4}$ señalan 3 etapas en la vida de las personas: la primera, a la que los autores denominan progreso, constituye la juventud; la segunda, a la que consideran de estabilización y equilibrio, corresponde a la edad adulta y la madurez; y la última, anterior a la muerte, es de retroceso o regresión, es decir, senectud. El propio Diccionario de la Lengua Española (DRAE) $)^{5}$ remite al término 'ancianidad' para referirse al último periodo de la vida ordinaria del hombre. El autor Fernández Garrido ${ }^{6}$ comenta que la vejez se ha desarrollado bajo la definición de patología y enfermedad, no

1 Instituto Nacional de Estadística, España en cifras (Madrid: Instituto Nacional de Estadística, 2004), consultado el 9 de agosto de 2014, http://www.ine.es/prodyser/espa_cifras/2014/files/ assets/basic-html/page1.html.

2 A. Abellán García y R. Pujol Rodríguez, "Un perfil de las personas mayores en España. Indicadores estadísticos básicos”, Informes envejecimiento en red, no. 10 (2015), consultado el 14 de julio, http://envejecimiento.csic.es/documentos/documentos/enred-indicadoresbasicos14. pdf.

3 Organización Mundial de la Salud, http://www.who.int/es/.

4 O. Fustinoni y D.A. Pasanante, "La tercera edad", Prensa Médica Argentina (1980): 66-85.

5 Real Academia Española, Diccionario de la Lengua Española (DRAE) (2012), 22 a ed., consultado el 5 de junio de 2014, http://www.rae.es/recursos/diccionarios/drae.

6 J. J Fernández Garrido, "Determinantes de la calidad de vida percibida por los ancianos de una residencia de $3^{a}$ edad en dos contextos socioculturales diferentes, España y Cuba" (tesis doctoral, Universitat de València, Departamento de Antropología Social, 2009), consultada el 2 de julio de 2014 . 
como el resultado del ciclo vital, y asegura que la vejez va más allá que cumplir años, puesto que realmente el paso de la edad madura a la ancianidad es estrictamente una cuestión social. Por último, Fernández Ballesteros ${ }^{7}$ señala que las personas mayores conforman un grupo de edad, ya que el envejecimiento un proceso que implica el paso del tiempo por el individuo.

Además de las diversas definiciones, existen diferentes términos para referirse a esta etapa de la vida del ser humano marcada por profundos cambios de todo tipo (psicológicos, fisiológicos, sociales, profesionales o económicos): ancianidad, tercera edad, adultos mayores, personas de edad avanzada, personas mayores, senectud y vejez, es decir, no hay un consenso en el término empleado. Por otro lado, tampoco hay unidad de criterio para establecer el umbral de edad que determina el paso de la edad adulta a la tercera edad. Así, por ejemplo, Lladó Bustamante ${ }^{8}$ considera entre las etapas de la vida: la presenilidad (45-60 años), la senilidad intermedia (60-70 años), la senilidad, vejez o ancianidad (70-80 años) y la longevidad (mayores de 80 años). Por su parte, Cordero del Castillo 9 señala que la tercera edad propiamente dicha se extiende desde los 65 a los 79 años, y de ahí en adelante se entra en la llamada la cuarta edad. Finalmente, para la OMS, las personas de edad avanzada son aquellas que tienen entre 60 y 74 años, las personas viejas o ancianas son las que tienen de 75 a 90 y de ahí en adelante se consideran grandes viejos o grandes longevos.

Ante tal avalancha de conceptos y diferencias en las edades para establecer la franja que engloba a este colectivo, en este artículo se usa el término "tercera edad" para hacer referencia a las personas con más de 65 años, sobre las cuales se han realizado numerosas investigaciones que las examinan desde diversas perspectivas. Así, se ha estudiado la relación de la tercera edad con las Tecnologías de la Información y la Comunicación (TIC), con la formación y los servicios informativos y con la ética social.

\section{Tercera edad y tic}

La relación entre las TIC y la tercera edad ha sido analizada desde diversos puntos de vista:

7 R. Fernández Ballesteros, "Posibilidades y limitaciones de la edad", Instituto de Mayores y Servicios Sociales dir. (Imerso), Libro blanco del envejecimiento y la vejez (Madrid: Imserso, 2011).

8 M. A. Lladó Bustamante, Geriatría, vejez y envejecimiento (Lima: Universidad Inca Garcilaso de la Vega, 1990).

9 P. Cordero del Castillo, "Situación social de las personas mayores en España", Humanismo y Trabajo Social 5 (2006): 161-195. 
a) Como herramienta de motivación: Pavón y Castellanos ${ }^{10}$ señalan, por una parte, que la tercera edad se motiva cuando descubre ciertas necesidades que se pueden satisfacer con el aprendizaje de las TIC pero, por otra, que estas tecnologías pueden provocarles miedo e incertidumbres, además de que aprender a usarlas puede ser complicado por sus posibles deterioros físicos, mentales o sociales.

b) Para buscar información de su interés en Internet: Pavón ${ }^{11}$ indica que las herramientas disponibles en la red que las personas mayores pueden utilizar para su adaptación a la sociedad son los buscadores de páginas web y listas de distribución que les ayuden a encontrar temas que les interesen y el correo electrónico, los chats y las videoconferencias para promover la comunicación por la red, ya sea escrita, oral o visual; Muñoz Márquez ${ }^{12}$ asegura que el envejecimiento de la población es un hecho, lo que ha despertado a la administración pública, la cual ha reaccionado con programas sociales, culturales, educativos y sanitarios acorde a las nuevas necesidades relacionadas con las TIC, proporcionándoles herramientas de Internet útiles que les permitan realizar actividades cotidianas sin moverse de casa; Martínez ${ }^{13}$ confirma la relevancia de las TIC en nuestras vidas y asegura que Internet se ha convertido en una de las herramientas sociales más importantes tanto para los jóvenes como para los mayores, quienes principalmente la usan para buscar temas de salud.

c) En la geriatría o gerontecnología: Loader ${ }^{14}$ señala que las políticas gubernamentales, donde la integración es la protagonista, podrían centralizar su visión en usar la informática como una herramienta complementaria a la salud; Chen y colaboradores ${ }^{15}$ consideran que la tecnología y su impacto en la rutina diaria es un hecho, por lo que hay que adaptarla para que las personas con dificultades puedan acceder a ella. Su estudio, que toma como muestra a 104 personas entre 60

10 F. Pavón y A. Castellanos, "El aprendizaje de los mayores y las nuevas tecnologías", en El aprendizaje de las personas mayores ante los retos del nuevo milenio, ed. de. E. Valenzuela y E. Alcalá (Madrid: Dykinson, 2000).

11 F. Pavón, "Internet para mayores", Comunicación y Pedagogía 165 (2000): 62-69, consultado el 5 de julio de 2014, http://www.redadultosmayores.com.ar/buscador/files/EDUCA010.pdf.

12 L. Muñoz Márquez, "Las personas mayores ante las tecnologías de la información y la comunicación. Estudio valorativo", Profesorado, Revista Currículum y Formación del Profesorado 6 , no. 1 (2002): 1-9.

13 R. Martínez, R. Cabecinhas y F. Loscertales, "Mayores universitarios en la red", Revista Cientifica de Educomunicación 19, no. 37 (2011): 89-95.

14 B. Loader, M. Hardey y L. Keeble, "Health Informatics for Older People: A Review of Ict Facilitated Integrated Care For Older People”, International Journal of Social Welfare 17, no. 1 (2008): 46-53.

15 K. Chen, H.S.A Chan y S.C. Chan, "Gerontechnology Acceptance by Older Hong Kong People”, International Society for Gerontechnology 11, no. 2 (2011): 102-103. 
y 91 años, muestra que las tecnologías más utilizadas por las personas mayores son el móvil, el reproductor de DVD/CD y la alarma de seguridad, y que no usan productos de alta tecnología, excepto Internet, el aprendizaje online y los juegos de ordenador; Gachet ${ }^{16}$ desarrolla el proyecto Virtual Cloud Carer que consiste en la creación de nuevos servicios para mayores dependientes y enfermos crónicos. usando tecnologías asociadas a Internet y a la computación en la nube con 3 objetivos: tecnológico, que busca desarrollar un sistema de telemonitorización y plataforma de telecontrol para las personas dependientes y los cuidadores; social, que pretende impedir la brecha social; y sanitario, que propone metas para mantenerse físicamente activos y facilitar al personal médico un seguimiento de las tareas. Zhou ${ }^{17}$ estudia las aplicaciones sanitarias basadas en las TIC, que se están desarrollando con el objetivo de mejorar la calidad de vida de las personas mayores. Se busca que sean independientes, que satisfagan sus necesidades personales mediante el uso de las TIC y sin asistentes personales. Para ello, desarrollan el programa Pervasive Service Computing for the Elderly, que intenta cubrir los deterioros mentales y físicos, las discapacidades y las limitaciones características de este colectivo. Chen y $\mathrm{Chan}^{18}$ investigan la aplicación de la gerontecnología en la vida cotidiana de las personas mayores de Hong Kong, indicando que en su vida diaria utilizan tecnologías básicas, como la televisión o el DVD, pero las que son más avanzadas, como el GPS (Global Positioning System), no las emplean habitualmente.

d) La brecha digital: Millán Tejedor ${ }^{19}$ señala la necesidad de acercar las TIC a la tercera edad para no aumentar la marginación social y, en consecuencia, la brecha social-digital. Considera que las TIC pueden ser una herramienta de ocio, de comunicación y de seguridad para la tercera edad, ya que se ha demostrado que Internet puede aumentar el funcionamiento cerebral, cognitivo, además de la autoestima y la creatividad, y que la telefonía móvil ayuda a aumentar la autonomía y

16 D. Gachet, M. de Buenaga, F. Aparicio y V. Padron, "Integrating Internet of Things and Cloud Computing for Health Services Provisioning: the Virtual Cloud Carer Project", Innovate Mobile and Internet Services in Ubiquitous Computing (IMIS), Sixth International Conference (2012): 918-921.

17 J. Zhou, X. Su, M. Ylianttila y J. Riekki, "Exploring Pervasive Service Computing Opportunities for Pursuing Successful Aging", Grid and Pervasive Computing Workshops (Berlín: Springer, 2012), 73-82

18 K. Chen K y A. Chan, "Gerontechnology Acceptance by Elderly Hong Kong Chinese: A Senior Technology Acceptance Model (STAM)”, Ergonomics 57, no. 5 (2014): 635-52.

19 R. Millán Tejedor, "La necesidad de acercar las TIC a la tercera edad", Bit 184 (2011): 7. 
la calidad de vida de los mayores. Pérez Serrano y Sarrate Capdevila ${ }^{20}$ consideran imprescindible facilitar a los colectivos más vulnerables (como la tercera edad) el acceso a las TIC, puesto que de no hacerlo se fomentaría la exclusión social. Si bien las TIC nos dan la oportunidad de crear espacios nuevos, difundir cultura o el cambio social, también provocan inseguridad e intranquilidad por su rápida actualización. La sociedad de la información está en pleno desarrollo, por lo que la educación electrónica es fundamental para no quedarse al margen. Aldana González ${ }^{21}$ investiga el diseño de una serie de acciones para acercar las TIC a los adultos, con el objetivo de reducir la brecha digital y estimular los procesos cognitivos, ya que uno de los estereotipos de nuestros mayores es el deterioro de este tipo de habilidades. Trabajan con una muestra de 30 alumnos de la tercera edad del Centro Universitario Ecapetec de la Universidad Autónoma del Estado de México y han obtenido como resultados: que la actitud hacia las TIC es positiva, con entusiasmo y disposición a aprender, pero con cierta desconfianza en su uso, que conforme se usan las TIC aumentan las preguntas al respecto y que la jerga tecnológica utilizada por los jóvenes es una de las mayores diferencias entre generaciones. Agudo Prado et al. ${ }^{22}$ señalan que en el proceso de senectud cuentan mucho las actitudes, aunque las acciones de la sociedad también influyen para que el envejecimiento sea activo y se pueda reducir la brecha digital. Los resultados de su trabajo confirman que las personas mayores son un grupo heterogéneo y que el uso de las tecnologías depende de los intereses y necesidades de cada persona. Según su estudio, los recursos más utilizados por la tercera edad son el ordenador (el 68.8\%) e Internet (el $50.7 \%$ ). Macías González y Manresa Yee ${ }^{23}$ realizan un trabajo sobre una muestra de 61 alumnos, de 56 a 86 años, del Programa Universitario para Mayores de la Universidad de les Illes Balears, con la finalidad de descubrir las motivaciones y dificultades en el uso de las TIC.

20 G. Pérez Serrano y M. Sarrate Capdevila, "Las TIC promotoras de inclusión social", Revista Española de Pedagogía 69, no. 249 (2011):237-254.

21 G. Aldana González, L. García Gómez y A. Jacobo Mata, "Las tecnologías de la información y comunicación (TIC) como alternativa a la estimulación de los procesos cognitivos en la vejez", Revista CPU-e 14 (2012): 153-166.

22 S. Agudo Prado, M. Pascual Sevillana y J. Fombona Cadavieco, "Usos de las herramientas digitales entre las personas mayores", Revista Científica de Educomunicación 20, no. 39 (2012): 293-201.

23 L. Macías González y C. Manresa Yee, "Mayores y nuevas tecnologías: motivaciones y dificultades", Ariadna: Cultura, Educación y Tecnologías 1, no. 1 (2013): 6-11. 
Caridad-Sebastián ${ }^{24}$ estudia el proyecto "Impolis: Indicadores para la medición del impacto en políticas TIC hacia la inclusión social”, el cual ha permitido crear un modelo para evaluar esas políticas de inserción social y orientar las decisiones al respecto. Según Hernando Gómez y Phillippi, ${ }^{25}$ en la actualidad no se ha analizado detenidamente cómo puede afectar la brecha digital al grupo de la tercera edad. La sistematización de políticas que contengan a este colectivo en la inclusión tecnológica es un paso muy importante para avanzar como sociedad. Para sumergirlos en estos avances, hay que incluir un estilo de aprendizaje que se centre en el uso de las TIC para su vida diaria: desde realizar gestiones bancarias hasta reencontrarse con un antiguo amigo.

e) Participación en redes sociales: Braun ${ }^{26}$ realizó un estudio en el que seleccionó a 124 personas de entre 60 y 90 años que fueron sometidas a una entrevista online sobre redes sociales. Se obtuvieron los siguientes resultados: es muy probable que una persona que utilice Internet acceda a alguna red social; la facilidad de su uso no es un factor determinante, existe cierta presión social que induce a utilizarlas y la confianza en dichas redes es directamente proporcional a la intención de usarlas. Muñoz Sáez ${ }^{27}$ desarrolla una aplicación de software que es una red social donde la tercera edad es la protagonista y cuyo objetivo es combatir el problema del aislamiento social de este colectivo. Esta aplicación es para dispositivos táctiles, con una interfaz muy intuitiva, que permite establecer comunicación por voz y por texto con otros miembros.

\section{Tercera edad y formación}

También se ha analizado la relación de la tercera edad con la formación desde diversos puntos de vista:

24 M. Caridad-Sebastián, A. Morales-García y F. García-López, "La alfabetización digital en España como medio de inclusión social: aplicación de un modelo de medición a través de indicadores", Historia y Comunicación Social 18 (2013): 455-469.

25 A. Hernando Gómez y A. Phillippi, "El desarrollo de la competencia mediática en personas mayores: una brecha pendiente”, Tema Central 124 (2013), consultado el 12 de mayo de 2014, http://www.revistachasqui.com/index.php/chasqui/article/view/81/62.

26 M. Braun, "Obstacles to Social Networking Website Use among Older Adults", Computers in Human Behavior 29, no. 3 (2013): 673-680.

27 D. Muñoz Sáez, "Red social para integración de personas de la tercera edad" (tesis Ingeniería, Universidad de Chile, 2013), consultado el 13 de junio de 2014, http://www.tesis.uchile.cl/ handle/2250/113800. 
a) La universidad: Blázquez Entonado ${ }^{28}$ señala que las personas adultas han cambiado radicalmente en España, puesto que si bien la jubilación significaba pasar a una situación de falta de actividad, en la actualidad se está reivindicando un nuevo concepto, ya que se prefiere trabajar más años, regresar a la Universidad o ser voluntarios. En el año 2002, más de 50 universidades españolas contaban con programas para la tercera edad. En la Universidad de Extremadura, por ejemplo, este programa, dirigido a personas mayores de 55 años, es un proyecto de desarrollo científico y cultural, con el fin de promover estos ámbitos y las relaciones intergeneracionales. La metodología de este tipo de programas debe ser activa, participativa, socializadora, indagadora y abierta para facilitar las oportunidades de crecimiento personal de las personas mayores. El aprendizaje en estas edades, comparándola con el infantil, va más despacio, se retiene peor y en menor cantidad, pero pueden retener cosas más esenciales y profundas. Tras la participación en estos programas, Blázquez Entonado, hizo un estudio sobre las motivaciones, preferencias y consideraciones de los participantes y obtuvo que el $50 \%$ de los mismos afirma que participa en este programa porque en su momento no tuvo oportunidad de estudiar, mientras que el $40 \%$ lo hace para ocupar su tiempo libre; Fernández-García ${ }^{29}$ siguiendo con la línea anterior, considera que el cambio demográfico conlleva otros cambios en la sociedad, como es el caso de la educación permanente o el aprendizaje a lo largo de la vida, siendo la Universidad uno de los factores que se encarga de este proyecto. En España se ofrece este tipo de educación para personas a partir de 50 años, donde el desarrollo científico, cultural y social para mejorar la calidad de vida de este colectivo es una necesidad. Los autores analizan la Universidad Nacional de Educación a Distancia (UNED) que creó el programa universitario "UNED Senior", dedicado a los adultos de 55 años, que consiste en ofrecer una formación de calidad conforme a sus intereses, demandas y expectativas. Una parte de su investigación analiza los resultados de una encuesta realizada a 639 alumnos matriculados en dicho programa de los cuales, el $15.5 \%$ eran personas mayores de 70 años, el $86.3 \%$ del total de participantes se matricularon en estos cursos para aprender más, seguido de un $78.6 \%$ que alega que es para mantenerse activo.

28 F. Blázquez Entonado, "Los mayores, nuevos alumnos de la universidad", Revista Interuniversitaria de Formación del Profesorado 45 (2002): 89-105.

29 A. Fernández-García, J. García Llamas y G. Pérez Serrano, "Los programas universitarios de mayores y su contribución al aprendizaje a lo largo de la vida", Revista Complutense de Educación 25, no. 2 (2014): 521-540. 
b) El aprendizaje formativo: Duay y Bryan ${ }^{30}$ aseguran que el cambio demográfico sufrido en los últimos años no sólo implicará cambios económicos, políticos y culturales, sino también educativos. Según su investigación, realizada sobre una muestra de 36 personas con una media de edad de 76.5 años, sólo el $22 \%$ de las personas mayores de 65 años han tenido la oportunidad de participar en cursos, frente al $55 \%$ de los adultos de 41 a 50 años y el $41 \%$ de los adultos de 51 a 65 . Gómez Bedoya ${ }^{31}$ indica que los desarrollos médicos y tecnológicos del siglo XX han provocado un crecimiento de la longevidad en el siglo XXI. La vejez comúnmente deriva en la disminución de la capacidad intelectual y cognitiva como consecuencia del desgaste que genera el proceso vital. Aunque hay pruebas que constatan la inexactitud de estas afirmaciones, no es menos cierto que el aprendizaje en la tercera edad presenta ciertos rasgos distintivos y peculiaridades que hay que tener en cuenta. Cuenca París ${ }^{32}$ explica que si bien la mayoría de los estudios están centrados en el desarrollo humano en las etapas infantiles y juveniles, desde hace un tiempo se ha cambiado esa visión y ahora hay más estudios sobre el aprendizaje en la tercera edad. Éstos se centran en el hecho de que la edad lleva consigo unas peculiaridades del momento evolutivo que hay que tener en cuenta, ya que condicionan su aprendizaje: posible deterioro físico, biológico y funcional, efectos psicosociales y diferencias funcionales a nivel cognitivo.

c) La alfabetización informacional: Marzal García-Quismondo ${ }^{33}$ considera que el avance de la sociedad de la información hacia la del conocimiento está cambiando el modelo educativo actual, cuyo objetivo no es la producción del conocimiento, sino la generación de éste. Por ello, es necesario desarrollar programas de Alfabetización Informacional (Alfin) que permitan al usuario seleccionar contenidos de calidad, para lo que es preciso dotarles de las destrezas, habilidades y competencias necesarias. Dichas competencias deben ser digitales, para que el usuario use las TIC eficazmente, y de lectoescritura, para que sepa se-

30 D. Duay y V. Bryan, "Learning in Later Life: What Seniors Want in A Learning Experience", Educational Gerontology 34, no. 12 (2008): 1070-1086.

31 M. Gómez Bedoya, "El aprendizaje en la tercera edad. Una aproximación en la clase de ELE: los aprendientes mayores japoneses en el Instituto Cervantes de Tokio", Biblioteca Virtual Redele 10 (2009): 164.

32 M. Cuenca París, "Motivación hacia el aprendizaje en las personas mayores más allá de los resultados y el rendimiento académico", Revista de Psicología y Educación 1, no. 6 (2011):239-254.

33 M. Marzal García-Quismondo, "La evaluación de los programas de alfabetización en información en la educación superior: estrategias e instrumentos", Revista de Universidad y Sociedad del Conocimiento 7, no. 2 (2010): 28-38. 
leccionar y organizar contenidos en la web mediante sus propios criterios, adecuándolos a sus necesidades. Evidentemente, coincidimos con el autor en que los programas de Alfin son fundamentales para el desarrollo social y económico de los países, pero además, consideramos imprescindible el diseño y la aplicación de dichos programas a todos los grupos sociales y, especialmente, a aquellos en riesgo de exclusión, como la tercera edad. En estos programas de Alfin, las bibliotecas juegan un papel destacado. Así lo señalan Pinto y Uribe Tirado, ${ }^{34}$ cuyo trabajo se concentra en el paso de la biblioteca pública a la híbrida con ayuda de las TIC. Para los autores:

La biblioteca pública híbrida es aquella que posee colecciones impresas y digitales, que facilita el acceso a dichas colecciones y suministra servicios de información y programas de formación híbridos (presenciales, semipresenciales, mediados por TIC, en ambientes virtuales de aprendizaje, etc.), es decir, una formación en Alfin híbrida, para así responder a las distintas necesidades y perfiles de los múltiples usuarios. ${ }^{35}$

La biblioteca pública debe ser partícipe de los cambios en la sociedad, por lo que debe adaptarse a otros servicios de la web 2.0 y abrir nuevas posibilidades de aprendizaje. Con estos programas se podrá combatir las diferencias sociales entre grupos de edades diversas (niños, jóvenes, adultos, tercera edad) y, en consecuencia, formar una sociedad sin exclusiones.

d) Los servicios informativos: se han publicado guías y realizado trabajos que muestran la implicación de las bibliotecas y los servicios de información con la tercera edad y, por consiguiente, la necesidad de incluir a este colectivo en la formación de los profesionales en Información y Documentación. Así lo recomiendan las "Guidelines for Library and Information Services to Older Adults" ${ }^{16}$ de la American Library Association (ALA), que constituyen un conjunto de 7 guías específicas para la tercera edad, que abarcan desde la recopilación de datos actualizados sobre este colectivo con el fin de incorporarlos a la planificación

34 M. Pinto y A. Uribe Tirado, "Las bibliotecas públicas híbridas en el marco de la alfabetización informacional”, Revista Española de Documentación Cientifica 35 (2012): 136-168, doi: 10.3989/redc.2012.mono.98.

35 Pinto y Tirado, "Las bibliotecas públicas híbridas en el marco de la alfabetización informacional”, 137.

36 Library Services to An Aging Population Committee, Reference Services Section, Reference and User Services Association of the American Library Association (1987) Revised 1999, Approved in 2008, consultado el 14 de agosto de 2015, http://www.ala.org/rusa/resources/ guidelines/libraryservices. 
y al presupuesto de la biblioteca (guía 1), hasta la formación del personal bibliotecario para servir a las personas mayores con profesionalidad (guía 7), pasando por crear colecciones, programas y servicios adecuados para este colectivo (guía 2), crear un ambiente seguro, cómodo y acogedor para ellos (guía 3), coordinar desde la biblioteca los servicios de información dedicados a los adultos mayores (guía 4), tener en cuenta a este colectivo en la programación de la biblioteca (guía 5) y atender a los adultos mayores que no puedan desplazarse hasta la biblioteca. Al contrario que la ALA, la International Federation of Library Associations and Institutions (IFLA) no ha desarrollado unas guías específicas para los adultos mayores, ya que los incluye en la división "Library Services" en la sección "Library Services to People with Special Needs Section" en la que se mencionan congresos como el celebrado en Quebec, Canadá, en 2008 con la temática "The World is Greying: Model Library Programs Serving Baby Boomers and Older Adults". ${ }^{37}$ Entre los autores que han investigado la relación de las bibliotecas y la tercera edad se encuentran García Gómez y Díaz Grau, ${ }^{38}$ quienes estudian y analizan experiencias y servicios que ofrecen diversas bibliotecas públicas para la tercera edad en sus sedes web: por ejemplo, las bibliotecas públicas de Vancouver (Canadá), Wellington (Nueva Zelanda), Birmingham (Reino Unido), Wilton o Cleveland (EEUU); o Joseph ${ }^{39}$ quien analiza el impacto de la tercera edad en las bibliotecas públicas de Nueva Gales del Sur en relación con el diseño de las instalaciones, dotación de recursos, estrategias de marketing, desarrollo de alianzas estratégicas o dotación de personal, y realiza un informe con recomendaciones para apoyar la planificación estratégica dentro de la red de bibliotecas públicas de Nueva Gales del Sur.

\section{Tercera edad y ética social}

La relación entre la tercera edad y la ética social ha sido investigada por autores como Pedrero Nieto, ${ }^{40}$ quien plantea que la mala planificación del futuro

37 International Federation of Library Associations and Institutions, http://www.ifla.org/ node/6198.

38 F. J. García Gómez y A. Díaz Grau, "Servicios bibliotecarios para la tercera edad en entornos web: experiencias desarrolladas en bibliotecas públicas”, El Profesional de la Información 13, no. 4 (2004): 272-280.

39 M. Joseph, Active, Engaged, Valued: Older People and NSW Public Libraries (2006), consultado el 12 de agosto de 2015, http://www.sl.nsw.gov.au/services/public_libraries/docs/ active_engaged_valued.pdf.

40 L. Pedrero Nieto, "Cuando la tercera edad nos alcanza. Reflexiones sobre dos cuestiones: cuando la tercera edad nos alcance y cuando yo alcance a la tercera edad", Archivo Geriátrico 5 , no. 4 (2004): 125-126. 
por parte de la sociedad puede hacer que la calidad de vida de los ancianos sea pésima y vacía; Cordero del Castillo ${ }^{41}$ considera que en una sociedad que defiende la ética social es preciso tomar medidas para proteger la salud, la economía, la autonomía y la dependencia de la tercera edad. Por ello, los resultados obtenidos por el autor respecto a las condiciones socioeconómicas de este colectivo en España hace unos años no dejaban al país en muy buen lugar, puesto que, según el gasto medio por unidad de consumo, la posición económica de nuestros mayores era inferior a la media de la población total. Polo González ${ }^{42}$ urge la redefinición y resocialización de la tercera edad por parte de los profesionales de la comunicación. La función de éstos es formar, informar y entretener, pero el problema viene en cómo se moldea la realidad, dando más importancia a los aspectos negativos del envejecimiento (gastos en sanidad) que a los positivos (mayor esperanza de vida). Rizo López ${ }^{43}$ indica que desde mediados del siglo XX la estructura familiar, así como sus roles, han ido evolucionando al mismo tiempo que la transformación demográfica. Este autor realiza un estudio sobre la imagen de la ancianidad a través del tiempo, que puede ilustrar la ética social de las culturas y sociedades a lo largo de la historia.

Actualmente la cultura occidental tiene una imagen de la vejez con prejuicios negativos, distinta del retrato ancestral de la senectud como mantenimiento de la tradición y el saber. La cultura oriental, sin embargo, aún mantiene esa imagen positiva de la ancianidad. López-Pérez y Fernández-Pinto ${ }^{44}$ ofrecen una nueva perspectiva en el estudio de la ética y la tercera edad relacionándola con la empatía, ya que ésta es una cualidad que subyace en muchas facetas del juicio y de la acción ética. La hipótesis de su estudio parte de la idea de que los componentes cognitivos de la empatía tienden a disminuir con la edad, mientras que en los componentes afectivos no se hallan diferencias significativas entre los distintos grupos de edad; ScheilAdlung y Bonan ${ }^{45}$ analizan la ética social desde el punto de vista sanitario. Según los autores, en Europa, la cobertura en la salud es casi universal gracias a los servicios nacionales, financiados con los impuestos y el seguro social, costeado a partir de las cotizaciones de la nómina.

41 Cordero del Castillo, "Situación social de las personas mayores en España", 161-195.

42 M. Polo González, "La resocialización de los mayores: una asignatura pendiente”, Comunicación e Cidadanía 4 (2006): 1-10.

43 A. Rizo López, "Tercera edad: diferentes percepciones y necesidad de relaciones basadas en una nueva ética social”, Kairos: Revista de Temas Sociales 20 (2007): 1-14.

44 B. López-Pérez B y I. Fernández-Pinto, "Diferencias de edad en empatía: desde la adolescencia hasta la tercera edad”, Ansiedad y Estrés 16, nos. 2-3 (2010): 139-150.

45 X. Scheil-Adlung y J. Bonan, "Brechas en la protección social de la salud y en los cuidados de larga duración en Europa: ¿bancarrota para la tercera edad?”, Revista Internacional de Seguridad Social 66, no. 1 (2013): 27-51. 
Una vez analizada en profundidad la relación de la tercera edad con diferentes ámbitos esenciales de la sociedad actual, parece lógico pensar que este grupo social, que está en continuo crecimiento, precisa del diseño de diferentes servicios capaces de satisfacer las nuevas necesidades que surjan en él. Evidentemente, la universidad no puede ni debe ser ajena a este intenso cambio social, por lo que los nuevos títulos de grado de las universidades españolas, independientemente de su disciplina, deberían incluir contenidos referentes a los adultos mayores o de la tercera edad y, más aún, los grados relacionados directamente con las TIC y la sociedad de la información, como es el caso del grado en Información y Documentación.

Es un hecho que el entorno de las bibliotecas y el resto de las unidades informativas debe ser una de las conexiones fundamentales que facilite a los mayores sumergirse en esta nueva sociedad proporcionándoles desde cursos de alfabetización digital hasta puntos de acceso a las TIC. Por ello, el objetivo fundamental de este trabajo es adaptar el actual título de grado en Información y Documentación de la Universidad de Extremadura (Unex) a nuevas oportunidades profesionales que parecen pasar desapercibidas a pesar de su importancia y constante crecimiento: las necesidades de la tercera edad en relación con la sociedad de la información y las TIC. Aunque parezca una paradoja, se podría considerar que la tercera edad es el "futuro" de las comunidades, por lo que es preciso formar profesionales en contenidos y en competencias ${ }^{46}$ que satisfagan sus necesidades, abriendo así una nueva vía laboral para los graduados en Información y Documentación. No obstante, no podemos olvidar que el Libro blanco de grado en Información y Documentación (2004) señala qué contenidos se incluyen en los planes de estudio similares en otros países y cuáles se deberían incluir en los distintos cursos, por lo que, aunque este ensayo focaliza su atención en el colectivo de la tercera edad, no deja al margen los contenidos previos ya existentes en las asignaturas analizadas.

\section{Material y metodología}

\section{Material}

Como el objetivo fundamental de este trabajo es adaptar el título de grado en Información y Documentación de la Unex en su modalidad presencial, a las necesidades de la tercera edad, para el diseño de un nuevo temario dedicado

46 A. Arias-Coello, C. Simón-Blas y J. Simón-Martín, "Competencias profesionales de los postgraduados en el máster de Gestión de la Documentación. Bibliotecas y Archivos desde la perspectiva de empleadores, estudiantes y profesores", Revista Española de Documentación Cientifica 37, no. 3 (2014), doi: http://dx.doi.org/10.3989/redc.2014.3.1121. 
a este colectivo se ha trabajado con los programas de las asignaturas del curso 2013-2014 disponibles en la página web de dicha titulación. ${ }^{47}$

En total, se han ideado temas para 40 asignaturas (cuyo mapa curricular aparece en la Tabla 1) que responden a la siguiente tipología: básicas y obligatorias, optativas seleccionadas, prácticas externas y trabajo fin de grado (todas las asignaturas son de 6 créditos). Estos temas diseñados no suplen los ya existentes, en los que se incluyen los cimientos teóricos y prácticos para una carrera profesional que ofrece al alumno las herramientas necesarias para adaptarse a cualquier escenario, sino que se añaden a los mismos.

Tabla 1. Mapa curricular del grado presencial en información y documentación en la Unex

\begin{tabular}{|c|c|}
\hline \multicolumn{2}{|c|}{ Primer curso } \\
\hline $\begin{array}{l}\text { 1. Diplomática y Producción Documental en las } \\
\text { Instituciones (básica, 1er. semestre) }\end{array}$ & $\begin{array}{l}\text { 6. Derecho de la Información y la Comunicación } \\
\text { (básica, 2do. semestre) }\end{array}$ \\
\hline 2. Información y Sociedad (básica, 1er. semestre) & 7. Edición Digital (básica, 2do. semestre) \\
\hline $\begin{array}{l}\text { 3. Introducción a la Estadística Documental } \\
\text { (básica, 1er. semestre) }\end{array}$ & $\begin{array}{l}\text { 8. Gestión y Administración en Empresas } \\
\text { de Comunicación y en Unidades Informativas } \\
\text { (básica, 2do. semestre) }\end{array}$ \\
\hline $\begin{array}{l}\text { 4. Introducción a la Tecnología de la Información y } \\
\text { la Comunicación (básica, 1er. semestre) }\end{array}$ & 9. Habilidades Comunicativas (básica, 2do. semestre) \\
\hline $\begin{array}{l}\text { 5. Teoría de la Comunicación y de la Información } \\
\text { (básica, 1er. semestre) }\end{array}$ & 10. Inglés (básica, 2do. semestre) \\
\hline \multicolumn{2}{|c|}{ Segundo curso } \\
\hline 11. Archivística (obligatoria, 1er. semestre) & 16. Análisis Documental (obligatoria, 2do. semestre) \\
\hline $\begin{array}{l}\text { 12. Fuentes de la Información y Recursos } \\
\text { Informativos (obligatoria, 1er. semestre) }\end{array}$ & $\begin{array}{l}\text { 17. Catalogación Descriptiva (obligatoria, } 2 \mathrm{do} . \\
\text { semestre) }\end{array}$ \\
\hline $\begin{array}{l}\text { 13. Fundamentos de la Información y } \\
\text { Documentación (obligatoria, 1er. semestre) }\end{array}$ & $\begin{array}{l}\text { 18. Lenguajes Documentales (obligatoria, } 2 \mathrm{do} . \\
\text { semestre) }\end{array}$ \\
\hline $\begin{array}{l}\text { 14. Fundamentos y Diseño de Bases de Datos } \\
\text { (obligatoria, 1er. semestre) }\end{array}$ & $\begin{array}{l}\text { 19. Organización de Colecciones (obligatoria, 2do. } \\
\text { semestre) }\end{array}$ \\
\hline $\begin{array}{l}\text { 15. Introducción a los Métodos Cuantitativos de la } \\
\text { Información (obligatoria, 1er. semestre) }\end{array}$ & $\begin{array}{l}\text { 20. Organización y Descripción de Archivos } \\
\text { (obligatoria, 2do. semestre) }\end{array}$ \\
\hline \multicolumn{2}{|c|}{ Tercer curso } \\
\hline $\begin{array}{l}\text { 21. Catalogación Automatizada (obligatoria, } \\
\text { 1er. semestre) }\end{array}$ & $\begin{array}{l}\text { 26. Análisis de Redes en Información y Documentación } \\
\text { (obligatoria, 2do. semestre) }\end{array}$ \\
\hline $\begin{array}{l}\text { 22. Documentación Informativa (obligatoria, } \\
\text { 1er. semestre) }\end{array}$ & $\begin{array}{l}\text { 27. Diseño y Dirección de Website (obligatoria, } \\
\text { 2do. semestre) }\end{array}$ \\
\hline
\end{tabular}

47 Universidad de Extremadura (Unex), http://www.unex.es/conoce-la-uex/centros/alcazaba/ informacion-academica/programas-asignaturas/programas-13-14. 


\begin{tabular}{|l|l|}
\hline $\begin{array}{l}\text { 23. Fuentes de Información Especializadas } \\
\text { (obligatoria, 1er. semestre) }\end{array}$ & $\begin{array}{l}\text { 28. Gestión de Documentos en Archivos (obligatoria, } \\
\text { 2do. semestre) }\end{array}$ \\
\hline $\begin{array}{l}\text { 24. Recuperación de la Información } \\
\text { obligatoria, 1er. semestre) }\end{array}$ & $\begin{array}{l}\text { 29. Procesamiento Avanzado de la Información y la } \\
\text { Documentación (obligatoria, 2do. semestre) }\end{array}$ \\
\hline $\begin{array}{l}\text { 25. Servicios de la Información (obligatoria, } \\
\text { 1er. semestre) }\end{array}$ & 30. Industrias Culturales (optativa, 2do. semestre) \\
\hline & \multicolumn{1}{|c|}{ Cuarto curso } \\
\hline $\begin{array}{l}\text { 31. Evaluación de la Actividad Científica } \\
\text { (obligatoria, 1er. semestre) }\end{array}$ & $\begin{array}{l}\text { 36. Documentación audiovisual (optativa, } \\
\text { 1er. semestre) }\end{array}$ \\
\hline $\begin{array}{l}\text { 32. Planificación, Auditoria y Evaluación de } \\
\text { Unidades de Información (obligatoria, 1er. } \\
\text { semestre) }\end{array}$ & $\begin{array}{l}\text { 37. Clasificación Documental en Bibliotecas } \\
\text { (obligatoria, 2do. semestre) }\end{array}$ \\
\hline $\begin{array}{l}\text { 33. Políticas y Sistemas de Información } \\
\text { (obligatoria, 1er. semestre) }\end{array}$ & $\begin{array}{l}\text { 38 y 39. Prácticas Externas (I y II) (obligatoria, 2do. } \\
\text { semestre) }\end{array}$ \\
\hline $\begin{array}{l}\text { 34. Ética y Deontología de la Información } \\
\text { (optativa, 1er. semestre) }\end{array}$ & 40. Trabajo Fin de Grado (obligatoria) \\
\hline 35. Paleografía (optativa, 1er. semestre) & \\
\hline
\end{tabular}

\section{Metodología}

Previamente al diseño, se han analizado detalladamente los programas de todos los títulos del grado en Información y Documentación del curso 20132014 de las diferentes universidades españolas que lo imparten (Tabla 2), con la intención de comprobar la representatividad de la tercera edad en ellos. En total, se han analizado 504 programas. Debido al ámbito geográfico en el que se enmarca la propuesta de nuevos temas (grado en Información y Documentación de la Universidad de Extremadura en España), al elevado número de programas recopilados y analizados y a la extensión de sus contenidos, el presente trabajo se centra en el análisis de las universidades españolas, sin entrar en la pesquisa de los planes de estudio de Información y Documentación en otros países.

Tabla 2. El grado en Información y Documentación en las universidades de España

\begin{tabular}{|l|l|}
\hline \multicolumn{1}{|c|}{ Universidad } & \multicolumn{1}{c|}{ Url } \\
\hline Universidad Carlos III de Madrid & $\begin{array}{l}\text { http://www.uc3m.es/ss/Satellite/UC3MInstitucional/es/ } \\
\text { TextoMixta/1371206649334/. }\end{array}$ \\
\hline $\begin{array}{l}\text { Universidad Complutense } \\
\text { de Madrid }\end{array}$ & $\begin{array}{l}\text { http://documentacion.ucm.es/estudios/2013-14/ } \\
\text { grado-informacionydocumentacion. }\end{array}$ \\
\hline
\end{tabular}




\begin{tabular}{|l|l|}
\hline Universidad de A. Coruña & $\begin{array}{l}\text { http://www.udc.es/ensino/detalleEstudio/index. } \\
\text { html?language=es\&codigo=710G02V01. }\end{array}$ \\
\hline Universidad de Alcalá de Henares & http://www.uah.es/documentacion/Estudios/titulaciones.htm. \\
\hline Universidad de Extremadura & $\begin{array}{l}\text { http://www.unex.es/conoce-la-uex/estructura-academica/ } \\
\text { centros/alcazaba/info_academica_centro/titulaciones/info_ } \\
\text { titulacion?idCentro=17\&idTitulacion=G52\&idPlan=1706. }\end{array}$ \\
\hline Universidad de Granada & http://fcd.ugr.es/static/GestorDocencia/*/GID. \\
\hline Universidad de León & $\begin{array}{l}\text { http://www.unileon.es/estudiantes/estudiantes-grado/oferta-de- } \\
\text { estudios/grado-en-informacion-y-documentacion. }\end{array}$ \\
\hline Universidad de Murcia & $\begin{array}{l}\text { http://www.um.es/web/comunicacion/contenido/estudios/grados/ } \\
\text { documentacion. }\end{array}$ \\
\hline Universidad de Salamanca & http://www.usal.es/webusal/node/474. \\
\hline Universidad de Valencia & $\begin{array}{l}\text { http://www.uv.es/uvweb/geografia-historia/es/ } \\
\text { estudios-grado/grados/oferta-grados/grados/grado- } \\
\text { informacion-documentacion-1285849131634/Titulacio. } \\
\text { html?id=1285847456671\&plantilla=GeografiaHistoria/Page/ } \\
\text { TPGDetaill. }\end{array}$ \\
\hline Universitat Oberta de Catalunya & $\begin{array}{l}\text { http://estudios.uoc.edu/es/grados-2-ciclo/informacion- } \\
\text { documentacion/presentación. }\end{array}$ \\
\hline Universidad de Zaragoza & $\begin{array}{l}\text { http://www.ub.edu/biblio/grau-dinformacio-i-documentacio/ } \\
\text { presentacio.html. }\end{array}$ \\
\hline
\end{tabular}

De este listado, sólo en el caso de la Universitat de Barcelona aparece una asignatura en la que se dedica un tema a la tercera edad (servicios para usuarios con necesidades especiales). No se han podido evaluar los temarios de la Universidad de Salamanca del curso 2013-2014 por no estar disponibles en su página web durante todo el periodo en el que se ha realizado el estudio de los grados nacionales. Sin embargo, como actualmente sí están disponibles los temarios del curso 2014-2015, se han revisado excepcionalmente y se ha comprobado que tampoco incluyen temas específicos sobre la tercera edad. Del mismo modo, los programas de la Universidad de Alcalá de Henares (aunque aparece uno en el listado de la Tabla 2) no se han podido analizar porque esta universidad ha dejado de impartir este título justo el pasado curso 2013-2014.

Una vez comprobada la escasísima representación de la tercera edad en el grado en Información y Documentación en la Universidad española y la ausencia de la misma en el Título en Extremadura, se procede a la adaptación del grado presencial en Información y Documentación de la Unex a la tercera edad, para lo que se idean temas al respecto en todas las asignaturas mencionadas en la Tabla 1. Es preciso aclarar que no se pretenden valorar los temarios actuales, sino aportar una imagen novedosa, diferente y necesaria 
de los mismos, adaptada a las posibles salidas profesionales de nuestros titulados y complementando los contenidos ya existentes con otros dedicados a la tercera edad.

Antes de abordar la propuesta de los analistas sobre el temario de la tercera edad para el grado en Información y Documentación de la Unex, se indaga en los planes de estudio de otros títulos de la Universidad española más relacionados con este colectivo. En la Tabla 3 se observan algunos ejemplos que demuestran la escasa extrapolación que dichos contenidos pueden tener para los estudios del grado en Información y Documentación, lo que hace necesario el diseño de contenidos específicos.

Tabla 3. Ejemplos de contenidos sobre la tercera edad en algunos títulos universitarios de España

\begin{tabular}{|c|c|}
\hline Título & Asignaturas (tercera edad) \\
\hline \multicolumn{2}{|c|}{ Universidad Complutense de Madrid } \\
\hline Grado en Educación Social & $\begin{array}{l}\text { - Psicopatología de la vida adulta y la vejez } \\
\text { - Educación de las personas mayores }\end{array}$ \\
\hline $\begin{array}{l}\text { Grado en Psicología } \\
\text { Itinerario Psicogerontología }\end{array}$ & $\begin{array}{l}\text { - Procesos cognitivos y aspectos emocionales en el } \\
\text { envejecimiento } \\
\text { - Neurobiología del envejecimiento e intervención cognitiva } \\
\text { - Bienestar y calidad de vida en personas mayores }\end{array}$ \\
\hline Grado en Terapia Ocupacional & - Geriatría \\
\hline \multicolumn{2}{|c|}{ Universidad de Granada } \\
\hline Grado en Enfermería & - Enfermería del envejecimiento \\
\hline Grado en Fisioterapia & $\begin{array}{l}\text { - Métodos en fisioterapia cardiorrespiratoria, } \\
\text { gerontológica y pediátrica } \\
\text { - Fisioterapia en patología cardiorrespiratoria, } \\
\text { gerontológica y pediátrica }\end{array}$ \\
\hline Grado en Logopedia & - Intervención Logopédica en Mayores \\
\hline Grado en Medicina & - Patología del sistema nervioso y geriatría \\
\hline Grado en Nutrición Humana y Dietética & · Alimentación en el envejecimiento \\
\hline Grado en Odontología & - Gerodontología \\
\hline Grado en Terapia Ocupacional & $\begin{array}{l}\text { - Geriatría } \\
\text { - Intervención en terapia ocupacional en discapacidad } \\
\text { músculo-esquelética y neurológica del niño y del anciano } \\
\text { - Intervención de terapia ocupacional en salud mental de la } \\
\text { infancia, adolescencia y personas mayores }\end{array}$ \\
\hline
\end{tabular}




\begin{tabular}{|l|l|}
\hline \multicolumn{2}{|c|}{ Universidad de Extremadura } \\
\hline $\begin{array}{l}\text { Grado en Enfermería (Badajoz, Cáceres, } \\
\text { Mérida y Plasencia) }\end{array}$ & - Enfermería del envejecimiento \\
\hline Grado en Medicina & - Medicina familiar, comunitaria y geriatría \\
\hline Grado en Terapia Ocupacional & $\begin{array}{l}\text { - Patología médico quirúrgica en la edad adulta y la vejez } \\
\text { - Aplicación de la terapia ocupacional en el adulto y la vejez }\end{array}$ \\
\hline Grado en Trabajo Social & - Trabajo social con personas mayores \\
\hline
\end{tabular}

\section{Resultados}

A continuación se exponen los temas ideados que se relacionan con la tercera edad en cada una de las asignaturas que conforman el plan de estudios del grado presencial en Información y Documentación de la Unex. Cada tema nuevo se compone de epígrafes acompañados de un breve resumen que explica su contenido. Como los temas diseñados para la tercera edad no suplen a los ya existentes, sino que se añaden a ellos, su numeración es consecutiva a los temas ya establecidos. ${ }^{48}$

Primer curso

\section{Diplomática y producción documental en las instituciones}

Tema 1. La evolución de la tercera edad a través de los documentos

7.1. La concepción de la tercera edad a lo largo de la Historia

En este epígrafe se estudian los roles y la opinión de la sociedad sobre la tercera edad a través del análisis de documentos que abarcan diferentes periodos históricos.

7.2. Actas notariales de defunción en España a través de los tiempos

Con este apartado se analiza cómo ha avanzado la longevidad en España desde el siglo XVIII para descubrir la evolución y la importancia de la tercera edad en nuestra sociedad a lo largo del tiempo.

2. Información y sociedad

Tema 6. La brecha social. La sociedad de la información y la tercera edad

6.1. El envejecimiento activo de la Sociedad de la Información

Se analiza qué es el envejecimiento activo. Los estereotipos que tiene la sociedad actual sobre la tercera edad

48 Universidad de Extremadura (Unex), http://www.unex.es/conoce-la-uex/centros/alcazaba/ informacion-academica/programas-asignaturas/programas-13-14. 
no son del todo acertados, si bien, un porcentaje de este colectivo se adhiere a la idea de no aprender más, hay otro más alto que quiere formar parte de la sociedad actual.

6.2. Teorías sociológicas sobre la tercera edad

En este apartado se comparan las distintas teorías sociológicas, desde los años sesenta hasta la actualidad, que justifican el comportamiento de la tercera edad.

6.3. Necesidades de la tercera edad

Se describen las necesidades informacionales específicas de este colectivo, atendiendo a la cultura, al sistema económico, al social y a la época.

3. Introducción a la estadística documental

\section{Tema 7. Fuentes estadísticas sobre la tercera edad}

7.1. Organismos especializados en la tercera edad

En esta parte se recopilan aquellos organismos nacionales e internacionales cuyas publicaciones estadísticas se refieren a la tercera edad (población, longevidad, necesidades, intereses, etc.).

\section{Introducción a la tecnología de la información y la comunicación}

\section{Tema 9. La relación entre las TIC y la tercera edad}

9.1. La alfabetización digital de la tercera edad

Se analiza la relación de la tercera edad y el manejo de las TIC. El continuo cambio de esta sociedad y su íntima relación con las TIC requiere la adaptación del modelo educativo y de aquellos colectivos en riesgo de exclusión. La alfabetización digital de la sociedad y, más concretamente, de la tercera edad, supone su reinserción en una sociedad donde el manejo y la gestión de la información son primordiales en la vida.

\section{Tema 10. Software y hardware para la tercera edad}

10.1. Diseño y aplicación de programas para la estimulación cognitiva

El uso de aplicaciones relacionadas con las TIC puede retrasar o mantener el deterioro mental de nuestros mayores. Para ello, se pueden diseñar aplicaciones de programa que estimulen la mente, con información sobre sus intereses y necesidades.

10.2. Hardware adaptado a la tercera edad

En este punto se estudian aquellos dispositivos que facilitan el acceso a las TIC ante las posibles deficiencias visuales y auditivas características de la tercera edad.

\section{Teoría de la comunicación y de la información}

Tema 6. La tercera edad en los medios de comunicación

6.1. La influencia de los medios de comunicación en la tercera edad

En la actualidad, el poder de los medios de comunicación es muy notable, creando a su merced estereotipos 
entre los colectivos más vulnerables. En esta parte se muestra la imagen de la tercera edad en diferentes países a través de los medios de comunicación.

\section{Derecho de la información y la comunicación}

\section{Tema 7. Protección de datos en centros asistenciales para la tercera edad}

7.1. Custodia de información y acceso a la información

Se estudia qué datos son custodiados por los centros asistenciales y el papel del profesional que cuida la información, haciendo especial distinción entre informes médicos e informes sociales. Además, se indica quién puede acceder a dicha información.

7.2. La figura del responsable legal

En algunos casos, la edad supone un deterioro mental que requiera la figura del responsable legal, para que reaccione en determinadas situaciones cuando el sujeto ya no pueda hacerlo por sí mismo. En este apartado se conocen los derechos que tiene esta persona y cuáles son sus limitaciones.

7.3. La teleasistencia en los centros sociales

Se estudia cuál es el tratamiento de la información obtenida a través de las cámaras ubicadas para cumplir el servicio de Teleasistencia.

\section{Edición digital}

Tema 5. Uso de los programas básicos para la tercera edad

\subsection{Microsoft Office}

Conocimiento del funcionamiento básico de las aplicaciones que engloba el paquete.

\subsection{Correo electrónico}

El correo electrónico puede servir como medio de comunicación, un sustituto de la antigua carta, pero al que se puede adjuntar imágenes, videos o sonidos. Es una buena alternativa al correo tradicional y una gran oportunidad para reinsertar a este colectivo en la Sociedad de la Información. Se estudian los principales servicios de email: Outlook, Yahoo! y Gmail, detallando cuáles son las opciones más accesibles para la tercera edad.

\subsection{Video llamadas}

En este epígrafe se aprende el funcionamiento de los principales programas que permitan realizar video llamadas, como Skype, Hangouts o Tango.

\subsection{Buscadores}

Se estudia el funcionamiento básico de los principales buscadores: Yahoo!, Google Chrome e Internet Explorer y se examina su amigabilidad de cara a la tercera edad.

Tema 6. Aplicaciones básicas para el uso cotidiano de la tercera edad

6.1. Banca online

Hay algunos bancos y cajas que ofrecen el servicio de la banca a distancia. Se aprende el manejo de las tareas básicas: transferencias y consultas de saldo. 


\subsection{Compras por Internet}

Se aprenden los principales servicios de pago seguros, como PayPal o Google Wallet.

6.3. Medicina online

Los principales centros de salud disponen de una página web donde se pueden pedir citas médicas, servicios que pueden ser útiles para la tercera edad, etc. En esta parte se identifican las principales páginas web de los centros de salud de Extremadura.

\section{Gestión y administración en empresas de comunicación y en unidades informativas}

Tema 8. Bienes y marketing en centros para la tercera edad

8.1. Bienes tangibles e intangibles en centros para la tercera edad

Se identifican los elementos que conforman los bienes tangibles (mobiliario) y los intangibles (filosofía de los profesionales) de los centros para la tercera edad.

8.2. Marketing para centros de la tercera edad

Se estudian dos tipos de marketing: el marketing de relaciones, que analiza las estrategias para que las actuaciones se encaminen a mejorar los servicios de los centros de cara a los mayores y el marketing interno, es decir, la conciencia del personal de estos centros sobre la importancia de su tarea dentro de ellos.

\section{Habilidades comunicativas}

Tema 5. Aspectos psico-fisiológicos de la comunicación en la tercera edad

5.1. El miedo al fracaso comunicativo

En este epígrafe se analizan las causas psicológicas que pueden influir en la falta de comunicación social de la tercera edad, en especial, la falta de autoestima.

\subsection{La disfunción del lenguaje oral}

Se estudian posibles deficiencias psicológicas y fisiológicas propias de la tercera edad que pueden interferir para que la comunicación oral no sea fluida, como la falta de autoestima.

5.3. El aprendizaje del lenguaje no verbal

Se enseñan los principios básicos del código de comunicación no verbal para solventar los problemas del lenguaje oral.

\section{Inglés}

\section{Tema 6. Inglés especializado en/para la tercera edad}

6.1. Vocabulario especializado en la tercera edad

Conocimiento de la versión en lengua inglesa del máximo vocabulario posible relacionado con la tercera edad.

6.2. Ocio especializado para la tercera edad

Conocimiento de recursos de entretenimiento y ocio en lengua inglesa básica para trabajar con la tercera edad. 
Tema 10. Los archivos y la tercera edad

10.1. Los archivos de las residencias de mayores

Se analiza la situación de los archivos de las residencias de mayores ubicadas en la ciudad de Badajoz con el fin de conocer su organización interna, así como su personal.

12. Fuentes de información y recursos informativos

Tema 6. Fuentes de información sobre la tercera edad

6.1. Las fuentes de información primarias para la tercera edad

En este epígrafe se recopilan las principales publicaciones que dediquen su espacio a la tercera edad y sus intereses, desde investigaciones a revistas de entretenimiento.

6.2. Las fuentes de información secundarias para la tercera edad

En este punto se elabora una información sintetizada y reorganizada a partir de las fuentes primarias, que permita acceder más rápido a éstas. Se hace especial hincapié en el análisis de las principales bases de datos nacionales e internacionales especializadas en la tercera edad (como Ageline mantenida por la Research Information Centre de la American Association of Retired Persons).

13. Fundamentos de información y documentación

Tema 5. Las habilidades informativas del profesional en centros de la tercera edad

5.1. La importancia de las habilidades informativas y la tercera edad

Análisis de las "Directrices sobre Desarrollo de Habilidades Informativas para el Aprendizaje Permanente" (IFLA, 2007), haciendo especial énfasis en las habilidades informativas necesarias para trabajar con la tercera edad.

14. Fundamentos y diseño de bases de datos

\section{Tema 8. Diseño de bases de datos especiales para la tercera edad}

8.1. Desarrollo de campos específicos para la tercera edad

Se enseña a identificar y a diseñar bases de datos con campos específicos para la tercera edad que incluyan características más propias de este colectivo (enfermedades crónicas, problemas visuales, deficiencias auditivas, tiempo libre disponible, disponibilidad para participar como voluntario, etc.).

8.2. Características de las bases de datos para la tercera edad

Se aprenden características que deben tener las bases de datos a la hora de diseñarse para adaptarse a la tercera edad (tamaño de la escritura, contraste de fondo, sonido, etc.). 


\section{Introducción a los métodos cuantitativos de la información}

\section{Tema 5. Bibliometría y tercera edad}

5.1. Las leyes bibliométricas en el entorno de la tercera edad

En este epígrafe, los alumnos/futuros profesionales aplican las tradicionales Leyes de la Bibliometría (Lotka, Bradford, Zipf) a la literatura científica sobre la tercera edad.

16. Análisis documental

\section{Tema 9. La indización, el resumen y la tercera edad}

9.1. Técnicas para indizar y resumir con la tercera edad

Teniendo en cuenta que las capacidades cognitivas van disminuyendo conforme se avanza en la tercera edad, los profesionales que trabajan en unidades informativas ubicadas en centros para mayores deben conocer técnicas que simplifiquen, tanto la extracción de palabras clave de los textos, como la elaboración de un resumen sobre el mismo, con el fin de enseñar dichas acciones a las personas mayores de dichos centros, y convertirse así en verdaderos transmisores de la alfabetización informacional para la tercera edad.

\section{Catalogación descriptiva}

Tema 7. ISBD adaptada a la tercera edad

7.1. Simplicidad de los campos de la descripción bibliográfica para la tercera edad

En este epígrafe se enseña al futuro profesional los campos imprescindibles para realizar una descripción (International Standard Bibliographic Description, ISBD) que pueda ser fácilmente interpretada en un catálogo por una persona mayor.

\section{Lenguajes documentales}

\section{Tema 10. Tesauros sobre la tercera edad}

10.1. Creación de una lista de encabezamientos dirigida a la tercera edad

A partir de las características y necesidades de la tercera edad, se elabora una lista de encabezamientos grupal sobre este colectivo social para su uso en los centros que ofrezcan servicios de bibliotecas a la tercera edad.

10.2. Creación de un tesauro dirigido a la tercera edad

A partir de las características y necesidades de la tercera edad, se elabora un tesauro grupal sobre este colectivo social, para su uso en los centros que ofrezcan servicios de bibliotecas a la tercera edad. 
Tema 6. Generar una colección especializada en/para la tercera edad 6.1. Búsqueda de colecciones sobre la tercera edad

En este epígrafe se realiza una recopilación de colecciones importantes nacionales e internacionales con documentos y materiales sobre las características de la tercera edad.

6.2. Búsqueda de colecciones para la tercera edad

Se estudian colecciones de bibliotecas nacionales e internacionales especiales para la tercera edad.

\section{Organización y descripción de archivos}

Tema 8. Organización y descripción de documentos en centros para la tercera edad

8.1. Funciones de los centros para la tercera edad

En este epígrafe se aprende el funcionamiento, la organización y las principales actividades de los centros para la tercera edad (residencias, hogares del pensionista, etc.) para poder realizar el cuadro de clasificación de las mismas

8.2. Creación del cuadro de clasificación

Atendiendo al punto anterior, se crea el cuadro de clasificación acorde a las necesidades de las instituciones.

Tercer curso

21. Catalogación automatizada

Tema 13. Catalogación especializada en tercera edad

13.1. Campos adicionales en el formato IBERMARC

Se identifican campos dirigidos a la tercera edad que se pueden incluir en el formato IBERMARC (Machine Readable Cataloging), como la indicación de la edad recomendada del material o la especialidad a la que va dirigida el material, enfocado a ayudar a la personas mayores a orientarse en la selección de los fondos.

\section{Documentación informativa}

Tema 8. Los medios de comunicación y la información sobre la tercera edad

8.1. La información sobre la tercera edad en la prensa

Análisis de noticias sobre la tercera edad en la prensa española online en un periodo determinado.

8.2. La información sobre la tercera edad en la televisión 
Análisis de noticias sobre la tercera edad en la televisión española online en un periodo determinado.

8.3. La información sobre la tercera edad en la radio

Análisis de noticias sobre la tercera edad en la radio española en un periodo determinado.

23. Fuentes de información especializadas

Tema 5. Fuentes de información especializadas en la salud de la tercera edad

5.1. Fuentes sobre instituciones sanitarias especializadas en la tercera edad

Se recopilan y analizan las páginas web de los principales centros sanitarios en España especializados en la tercera edad.

24. Recuperación de información

Tema 5. Sistemas de recuperación y la tercera edad

5.1. Los sistemas de recuperación adaptados a la tercera edad

Creación y desarrollo de un sistema de recuperación intuitivo y de fácil manejo para este colectivo, por ejemplo, un listado alfabético con los principales términos que representen sus necesidades.

25. Servicios de información

\section{Servicios de bibliotecas en centros para la tercera edad}

6.1. Servicios bibliotecarios especiales para la tercera edad

Se enseña a los alumnos/futuros profesionales qué servicios bibliotecarios son necesarios en los centros para la tercera edad y cómo se debe enseñar su funcionamiento a los usuarios del centro, por ejemplo, el uso de la clasificación decimal universal

6.2. Servicios de archivos

Se enseña a los alumnos/futuros profesionales qué servicios archivísticos son necesarios en los centros para la tercera edad y cómo se debe enseñar su funcionamiento a los usuarios del centro, por ejemplo, el uso de un inventario.

\section{Análisis de redes en información y documentación}

Tema 5. Las redes sociales en la tercera edad

5.1. Las redes sociales sobre la tercera edad

Se identifican cuáles son las principales redes sociales nacionales e internacionales sobre la tercera edad.

5.2. La tercera edad y las redes sociales

En este epígrafe se analiza la participación de la tercera edad en redes sociales como Facebook y Twitter. 
27. Diseño y dirección de websites

Tema 5. Diseño de webs accesibles para la tercera edad

5.1 Accesibilidad web

Conocimiento de las pautas internacionales de accesibilidad web (Web Content Accesibility Guidelines, wcag 2.0) y estudio pormenorizado de aquellas más apropiadas para la tercera edad.

5.2 Diseño de un web específico para la tercera edad

En este apartado el alumno diseña una web con características de accesibilidad y de contenido propias para la tercera edad.

\section{Gestión de documentos en archivos}

Tema 7. Los documentos electrónicos y la tercera edad en archivos

7.1. Software de gestión documental para archivos de centros de la tercera edad.

En este apartado se conocen los principales programas informáticos especializados en la gestión de la documentación en centros para la tercera edad.

7.2. La firma digital y la tercera edad

Este punto se expone cuáles son los principales beneficios que adquiere este sector de la población con el uso de la firma digital, como el ahorro de tiempo en los trámites que puedan tener con la administración.

\section{Procesamiento avanzado de la información y la documentación}

Tema 6. Procesamiento de la información y la tercera edad

6.1. El procesamiento de la información por la tercera edad

El conocimiento sobre cómo se procesa la información es fundamental para acercar un producto y/o servicio a cualquier grupo social, incluida la tercera edad. Por eso, en este apartado los alumnos aprenden cómo procesan la información los mayores, con el fin de adaptar los productos y/o servicios informativos a dicho colectivo (por ejemplo, el almacenamiento de la información sigue técnicas nemotécnicas propias, los sistemas de conducción de información son más rígidos, etc.).

6.2. Técnicas para activar el procesamiento de la información en la tercera edad

En este caso, se aprenden técnicas para activar el proceso informativo en los mayores (como la técnica de lugares que conlleva: prestar atención y repetir lo que se pretende recordar).

30. Industrias culturales (optativa)

Tema 7. Editoriales especializadas en la tercera edad

7.1. Editoriales españolas sobre la tercera edad 
Conocimiento de las editoriales españolas online especializadas en la tercera edad. Análisis de sus catálogos para descubrir las principales líneas de interés editorial en España sobre este colectivo.

7.2. Editoriales internacionales sobre la tercera edad

Conocimiento de las editoriales internacionales online especializadas en la tercera edad. Análisis de sus catálogos para descubrir las principales líneas de interés editorial a escala internacional sobre este colectivo.

\section{Cuarto curso}

\section{Evaluación de la actividad científica}

\section{Tema 5. Evaluación científica sobre la tercera edad}

5.1. Análisis de la producción científica sobre la tercera edad

En los últimos años este grupo social ha crecido bastante conformando una gran parte de la sociedad mundial. En este punto se estudia su influencia en las bases de datos y en las revistas, así como los principales autores y líneas de investigación sobre este colectivo, con el fin de descubrir la importancia de este tema en el campo de la investigación.

\section{Planificación, auditoría y evaluación de unidades de información}

Tema 6. La auditoría y evaluación de centros de la tercera edad

6.1. Auditorías de centros de la tercera edad

En este epígrafe se comprueba si los centros de mayores (residencias de la tercera edad, el hogar del pensionista, etc.) son auditados o no, y en caso afirmativo, se analizan dichas auditorías para comprobar su operatividad.

6.2. Evaluación de centros de la tercera edad

Se desarrollan indicadores de evaluación específicos para este tipo de centros (por ejemplo, tasa de incremento anual del no. de personas mayores que asisten a la biblioteca de la residencia de la tercera edad, etc.)

\section{Políticas y sistemas de información}

\section{Tema 9. Políticas enfocadas a la tercera edad}

\subsection{Directivas europeas y su influencia en la tercera edad}

En este punto se conocen cuáles han sido las repercusiones de diversas medidas europeas en la tercera edad. Por ejemplo: el libro Blanco Política Social Europea. Un paso adelante para la Unión (1999), e-Europa Estrategias para la creación de empleo en la Sociedad de la Información, la Directiva 98/10/CE 1 de abril de 1998 sobre el acceso a la telefonía o la Directiva 99/5/CE 7 de abril de 1999 sobre la creación de aplicaciones a personas con discapacidad. 
34. Ética y deontología de la información (optativa)

\section{Tema 5. La ética social y la tercera edad}

5.1 La tercera edad dentro de la sociedad de la información

Se estudian cuáles son los motivos por los que las personas mayores no acaban de encajar en esta nueva sociedad.

5.2 Cómo evitar la infoexclusión

La infoexclusión es causa de la brecha digital, por lo que las bibliotecas, que no dejan de ser servicios públicos, deben realizar actividades o cursos enfocados a salvar esta exclusión. Por ello, en este epígrafe se estudian algunas actividades que las bibliotecas deben realizar al respecto (como el desarrollo de cursos de alfabetización informacional para los usuarios de la tercera edad).

35. Paleografía (optativa)

Tema 6. Tipos de escritura en documentos antiguos sobre la tercera edad

6.1. Análisis de documentos sobre la tercera edad desde el punto de vista de su escritura

Tras localizar diversos documentos de periodos históricos diferentes relacionados con la tercera edad, se analiza la tipología de su escritura.

36. Documentación audiovisual (optativa)

Tema 5. Gestión de imágenes y videos para la tercera edad

5.1. La estimulación cognitiva a través de imágenes y videos

Uno de los usos que puede resultar positivo a este colectivo es la estimulación de la memoria a través de imágenes y videos que reaviven sus recuerdos y conocimientos almacenados en el pasado, ya que es una de las deficiencias que conlleva la vejez. Por ello, en este tema el futuro profesional estudia cómo gestionar y almacenar la información recogida en estos formatos.

\section{Clasificación documental en bibliotecas (optativa)}

Tema 6. Clasificación Decimal Universal (CDU) adaptada a la tercera edad

6.1. CDU simplificada para la tercera edad

Al igual que en bibliotecas escolares existe una cdu simplificada para su uso en los centros escolares, en este epígrafe se diseña una cdu más simple para clasificar los fondos de una biblioteca de un centro de la tercera edad, con la finalidad de que estos usuarios localicen el material con mayor facilidad. 
En este caso, los alumnos del grado eligen unidades de información de centros de la tercera edad para realizar sus prácticas. Así aprenden el funcionamiento, tanto de la biblioteca 0 archivo en el que están realizando sus prácticas, como del propio centro de la tercera edad en el que se halla ubicado. Esto les permite entrar en contacto con un colectivo que, en principio, por edad está alejado de ellos, enriqueciéndose profesional y personalmente.

40.Trabajo fin de grado (TFG)*

*TFG relacionado con la tercera edad

Una vez que los alumnos hayan estudiado el grado en Información y Documentación incluyendo en todas las asignaturas temas sobre la tercera edad, estarán en disposición de realizar un TFG enfocado a alguna de las líneas sobre la tercera edad propuestas en su título. Este hecho repercutirá positivamente, tanto en el alumno, como en la propia sociedad.

\section{conclusiones}

Delimitar el concepto de tercera edad resulta muy complejo, puesto que existen numerosas definiciones, terminologías y edades para englobar a este colectivo. Si bien la bibliografía existente sobre la tercera edad y su relación con las TIC, la formación y la ética social es muy numerosa, no es tan exhaustiva cuando se trata de trabajos concretos sobre la tercera edad y el mundo de la información y la documentación. No obstante, se han encontrado algunos trabajos y recomendaciones internacionales relacionados con la alfabetización informacional y los servicios de información para la tercera edad.

Respecto a la tercera edad y las TIC, es una realidad que éstas deben estar al alcance de todas las personas, independientemente del colectivo al que pertenezcan, para así evitar la infoexclusión; es decir, la brecha intergeneracional y social que produce el desconocimiento de las TIC por parte de la tercera edad, sin duda, provoca su exclusión de la actual sociedad de la información.

La universidad tiene mucho que decir a este respecto, ya que es una de las claves de la inmersión de los mayores en la sociedad actual. Esta institución acepta que se puede aprender a cualquier edad y a lo largo del ciclo vital. Por ello, desarrolla programas con una metodología activa, participativa, socializadora, indagadora y abierta para facilitar las oportunidades de crecimiento personal de los adultos mayores. Pero además, los títulos universitarios, independientemente de su disciplina y de sus fronteras geográficas, deben incluir contenidos referentes a la tercera edad y, más aún, los 
títulos relacionados directamente con las TIC y la sociedad de la información, como es el caso de los estudios universitarios en Información y Documentación.

En cuanto a la ética social y su relación con la vejez, es preciso tomar medidas para proteger la salud, la economía, la autonomía y la dependencia de la tercera edad. Sin embargo, aunque en Europa la cobertura en la salud es casi universal gracias a los servicios nacionales de salud financiados con los impuestos y el seguro social generado con las cotizaciones de las nóminas, no ocurre lo mismo en otros continentes y países.

Se han publicado guías a escala internacional sobre la relación entre los servicios de información y la tercera edad, demostrando la necesidad de incluir a este colectivo en la formación de los profesionales en información y documentación. En concreto, la American Library Association (ALA) ha publicado las "Guidelines for Library and Information Services to Older Adults" que constituyen un conjunto de 7 guías específicas para la tercera edad. En concreto, la guía número 7 indica la necesidad de formar al personal bibliotecario para servir a las personas mayores con profesionalidad.

Este colectivo, cada vez más numeroso, supone una cantera muy importante para las salidas profesionales de los universitarios actuales y futuros. Por ello, tras analizar los 504 programas de todos los títulos universitarios en Información y Documentación de las universidades españolas que lo imparten, y observar la mínima representación de la tercera edad en ellos (solo se ha localizado un tema en la Universitat de Barcelona), se han diseñado temas para las 40 asignaturas del título que se imparte la Universidad de Extremadura. Se han ideado contenidos muy variados que abarcan muchos aspectos sobre la información, la documentación y la tercera edad. Éstos, extrapolables a otros países, podrían estar presentes en la enseñanza del grado con el fin de incrementar las salidas profesionales del título y, por consiguiente, de los egresados en Información y Documentación.

Aunque los contenidos ideados en determinadas asignaturas podrían generar cierta controversia, el presente trabajo se plantea como una propuesta que no ha sido abordada con anterioridad por ningún título de grado en Información y Documentación de la Universidad española, lo que podría abrir nuevos caminos también enfocados en el desarrollo de alguna maestría universitaria en Información y Documentación especializada en la tercera edad o de cursos de formación sobre el tema. 


\section{Referencias}

Abellán García, A. y R. Pujol Rodríguez. 2015. "Un perfil de las personas mayores en España. Indicadores estadísticos básicos”. Informes envejecimiento en red, no. 10 (2015). Consultado el 14 de julio de 2015. http://envejecimiento.csic.es/documentos/documentos/ enred-indicadoresbasicos14.pdf.

Agudo Prado, S., M. Pascual Sevillana y J. Fombona Cadavieco. 2012. "Usos de las herramientas digitales entre las personas mayores". Revista Científica de Educomunicación 20, no. 39: 293-201.

Aldana González, G., L. García Gómez y A. Jacobo Mata. 2012. "Las tecnologías de la información y comunicación (TIC) como alternativa a la estimulación de los procesos cognitivos en la vejez". Revista CPU-e 14: 153-166.

Arias-Coello, A., C. Simón-Blas y J. Simón-Martín. 2014. "Competencias profesionales de los postgraduados en el máster de Gestión de la Documentación, Bibliotecas y Archivos desde la perspectiva de empleadores, estudiantes y profesores". Revista Española de Documentación Científica 37, no. 3. doi: http://dx.doi.org/10.3989/ redc.2014.3.1121.

Blázquez Entonado, F. 2002. "Los mayores, nuevos alumnos de la universidad". Revista Interuniversitaria de Formación del Profesorado 45: 89-105.

Braun, M. 2013. "Obstacles to Social Networking Website Use Among Older Adults". Computers in Human Behavior 29, no. 3: 673-680.

Caridad-Sebastián M., A. Morales-García y F. García-López. 2013. "La alfabetización digital en España como medio de inclusión social: aplicación de un modelo de medición a través de indicadores". Historia y Comunicación Social 18: 455-469.

Chen K. y Chan A. 2014. "Gerontechnology Acceptance by Elderly Hong Kong Chinese: A Senior Technology Acceptance Model (stam)". Ergonomics 57, no. 5: 635-52.

Chen, K, H.S.A Chan y S. C. Chan. 2011. "Gerontechnology Acceptance by Older Hong Kong People”. International Society for Gerontechnology 11, no. 2: 102-103.

Cordero del Castillo, P. 2006. "Situación social de las personas mayores en España”. Humanismo y Trabajo Social 5: 161-195.

Cuenca París, M. 2011. "Motivación hacia el aprendizaje en las personas mayores más allá de los resultados y el rendimiento académico". Revista de Psicología y Educación 1, no. 6:239-254.

Duay, D. y V. Bryan. 2008. "Learning in Later Life: What Seniors Want in a Learning Experience”. Educational Gerontology 34, no. 12: 1070-1086.

Fernández Ballesteros, R. 2011. "Posibilidades y limitaciones de la edad", en Libro blanco del envejecimiento y la vejez, dir. Instituto de Mayores y Servicios Sociales. Madrid: Imserso. 
Fernández-García, A., J. García Llamas y G. Pérez Serrano. 2014. "Los programas universitarios de mayores y su contribución al aprendizaje a lo largo de la vida". Revista Complutense de Educación 25, no. 2: 521-540.

Fernández Garrido, J. J. 2009. "Determinantes de la calidad de vida percibida por los ancianos de una residencia de $3^{a}$ edad en dos contextos socioculturales diferentes, España y Cuba". Tesis doctoral, Universitat de València, Departamento de Antropología Social. Consultada el 2 de julio de 2014. http://www.researchgate. net/publication/50819378_Determinantes_de_la_calidad_de_ vida_percibida_por_los_ancianos_de_una_residencia_de_tercera _edad_en_dos_contextos_socioculturales_diferentes_Espaa_y_Cuba.

Fustinoni, O. y D.A. Pasanante. 1980. "La tercera edad". Prensa Médica Argentina: 66-85.

Gachet, D., M de Buenaga, F. Aparicio y V. Padron. 2012. "Integrating Internet of Things and Cloud Computing for Health Services Provisioning: The Virtual Cloud Carer Project", en Innovate Mobile and Internet Services in Ubiquitous Computing (IMIS), Sixth International Conference: 918-921.

García Gómez, F. J. y A. Díaz Grau. 2004. "Servicios bibliotecarios para la tercera edad en entornos web: experiencias desarrolladas en bibliotecas públicas". El Profesional de la Información 13, no. 4: 272-280.

Gómez Bedoya, M. 2009. "El aprendizaje en la tercera edad. Una aproximación en la clase de ELE: los aprendientes mayores japoneses en el Instituto Cervantes de Tokio". Biblioteca Virtual Redele 10: 164.

Hernando Gómez, A. y A. Phillippi. 2013. "El desarrollo de la competencia mediática en personas mayores: Una brecha pendiente". Tema central 124. Consultado el 12 de mayo de 2014. http://www. revistachasqui.com/index.php/chasqui/article/view/81/62.

Instituto Nacional de Estadística. 2014. España en cifras. Madrid: Instituto Nacional de Estadística. Consultado el 9 de agosto de 2014. http://www.ine.es/prodyser/espa_cifras/2014/files/assets/basic $\mathrm{html} /$ page1.html.

Joseph, M. 2006. Active, Engaged, Valued: Older People and NSW Public Libraries. Consultado el 12 de agosto de 2015. http://www.sl.nsw. gov.au/services/public_libraries/docs/active_engaged_valued.pdf.

Library Services to an Aging Population Committee. 2008. Reference Services Section, Reference and User Services Association of the American Library Association. Consultado el 14 de agosto de 2015. http://www.ala.org/rusa/resources/guidelines/libraryservices.

Libro blanco de grado en información y documentación. 2004. Madrid: Agencia Nacional de Evaluación de la Calidad y Acreditación. Consultado el 18 de mayo de 2012. http://www.aneca.es/media /150424/libroblanco_jun05_documentacion.pdf\#10.

Lladó Bustamante, M. A. 1990. Geriatría, vejez y envejecimiento. Lima: Universidad Inca Garcilaso de la Vega. 
Loader, B., M. Hardey y L. Keeble. 2008. "Health Informatics for Older People: A Review of ICT Facilitated Integrated Care for Older People". International Journal of Social Welfare 17 no. 1:46-53.

López-Pérez B. e I. Fernández-Pinto. 2010. "Diferencias de edad en empatía: desde la adolescencia hasta la tercera edad”. Ansiedad y Estrés 16, no. 2-3: 139-150.

Macías González, L. y C. Manresa Yee. 2013. "Mayores y nuevas tecnologías: motivaciones y dificultades". Ariadna: Cultura, Educación y Tecnologías 1, no. 1: 6-11.

Martínez, R., R. Cabecinhas y F. Loscertales. 2011. "Mayores universitarios en la red". Revista Cientifica de Educomunicación 19, no. 37: 89-95.

Marzal García-Quismondo, M. 2010. "La evaluación de los programas de alfabetización en información en la educación superior: estrategias e instrumentos". Revista de Universidad y Sociedad del Conocimiento 7, no. 2: 28-38.

Millán Tejedor, R. 2011. "La necesidad de acercar las TIC a la tercera edad". Bit 184: 7.

Muñoz Márquez, L. 2002. "Las personas mayores ante las tecnologías de la información y la comunicación. Estudio valorativo". Profesorado, revista currículum y formación del profesorado 6, no. 1: 1-9.

Muñoz Sáez, D. s. a. "Red social para integración de personas de la tercera edad". Tesis de ingeniería, Universidad de Chile. Consultada el 13 de julio de 2014. http://www.tesis.uchile.cl/handle /2250/113800.

Pavón, F. 2000. "Internet para mayores". Comunicación y pedagogía 165: 62-69. Consultada el 5 de julio de 2014. http://www. redadultosmayores.com.ar/buscador/files/EDUCA010.pdf.

Pavón, F. y A. Castellanos. 2000. "El aprendizaje de los mayores y las nuevas tecnologías". En El aprendizaje de las personas mayores ante los retos del nuevo milenio. Editado por Valenzuela, E. y Alcalá, E. Dykinson: Madrid.

Pedrero Nieto, L. 2004. "Cuando la tercera edad nos alcanza. Reflexiones sobre dos cuestiones: cuando la tercera edad nos alcance y cuando yo alcance a la tercera edad". Archivo Geriátrico 5, no. 4: $125-126$.

Pérez Serrano, G. y M. Sarrate Capdevila. 2011. "Las TIC promotoras de inclusión social”. Revista Española de Pedagogía 69, no. 249: 237-254.

Pinto, M. y A. Uribe Tirado. 2012. "Las bibliotecas públicas híbridas en el marco de la alfabetización informacional”. Revista Española de Documentación Científica 35: 136-168. doi:10.3989/redc.2012. mono.980.

Polo González, M. 2012. "La resocialización de los mayores: una asignatura pendiente". Comunicación e Cidadanía 4: 1-10.

Real Academia Española. 2012. Diccionario de la Lengua Española (DRAE), $22^{a}$ ed. Consultado el 5 de junio de 2014. http://www.rae. es/recursos/diccionarios/drae. 
Rizo López, A. 2007. "Tercera edad: diferentes percepciones y necesidad de relaciones basadas en una nueva ética social". Kairos: Revista de Temas Sociales 20: 1-14.

Scheil-Adlung, X. y J. Bonan. 2013. "Brechas en la protección social de la salud y en los cuidados de larga duración en Europa: ¿bancarrota para la tercera edad?". Revista Internacional de Seguridad Social 66, no.1: 27-51.

Zhou, J., X. Su, M. Ylianttila y J. Riekki. 2012. "Exploring Pervasive Service Computing Opportunities for Pursuing Successful Agein". Grid and Pervasive Computing Workshops. Berlín: Springer.

\section{Para citar este artículo:}

Faba-Pérez, Cristina y Rocío Patiño-Agudo. "La formación de profesionales universitarios en información y documentación desde una nueva perspectiva: la tercera edad”. Investigación Bibliotecológica, 31, no. 71 (enero-abril 2017): 17-51.

DOI:htpp://dx.doi.org/10.22201/iibi.0187358xp.2017.71.57808

$\infty$ 